18. Корниенко В.О., Нецветов М.В. Влияние отрицательных температур на механическую устойчивость дуба красного (Quercus rubra L.) // Промышленная ботаника. 2013. Вып. 13. С. 180-186.

19. Корниенко В.О., Нецветов М.В. Криоскопия влаги и температурная зависимость модуля упругости древесины // Вісті Біосферного заповідника «Асканія-Нова». 2014. Т. 16. С. 88-94.

20. Корниенко В.О., Такташов Р.Б., Нецветов М.В. Сильватизирующий эффект и динамика насаждений Ailanthus altissima (Mill.) Swingle на угольных отвалах // Промышленная ботаника. 2014. Вып. 14. С. $69-$ 76.

21. Корниенко B.O. Influence of cyclic freezing and thawing upon the mechanical stability of pedunculate oak Quercus robur L. // 5 съезд биофизиков: матер. междунар. конф. Ростов-на-Дону, 2015. С. 360.
22. Netsvetov M., Sergeyev M., Nikulina V., Korniyenko V., Prokopuk Yu. The climate to growth relationships of pedunculate oak in steppe // Dendrochronologia. 2017. № 44. P. 31-38.

23. Правила создания, содержания и охраны зеленых насаждений города Москвы. М.: Департамент природопользования и охраны окружающей среды, 2012. $138 \mathrm{c}$.

24. Niklas K.J. Plant biomechanics: an engineering approach to plant form and function. Chicago: University of Chicago Press. 1992. 622 p.

25. Niklas K.J. Worldwide correlations of mechanical properties and green wood density // American Journal of Botany. 2010. Vol. 97 (10). P. 1587-1594.

26. Tropical Tree Physiology: Adaptations and Responses in a Changing Environment / Ed. Goldstein G., Santiago L.S. 2016. Vol 6. 467 p.

\title{
A NEW METHODOLOGICAL APPROACH TO EVALUATION OF MECHANICAL RESISTANCE OF GREEN PLANTINGS IN URBAN ENVIRONMENTS
}

(C) 2018

Kornienko Vladimir Olegovich, senior lecturer of Biophysics Department

Donetsk National University (Donetsk, Donetsk People's Republic)

Prikhodko Svetlana Anatolyevna, candidate of biological sciences, senior researcher, director Donetsk Botanical Garden (Donetsk, Donetsk People's Republic)

Abstract. The trees growing in urban environments are exposed to the highest pressure of negative exogenous factors and, consequently, many tree species come to the critical age and become hazardous. A complex approach to evaluate the condition of green plantings under the technogenous load using visual, instrumental, biomechanical etc. methods allows timely and reliable identification of hazardous trees. For this purpose, we developed a new methodology of determining the hazardous degree of trees in residential areas. This method is based on the accounts of tree mechanical hardiness evaluation and up-to-date instrumental research data to be used by municipal services employed in plantings monitoring and care. The main parameters are: age, diameter of the base, diameter at height, trunk girth at the base, trunk girth at a height of $1,3 \mathrm{~m}$, the height of the tree, the angle of inclination of the trunk, the vital status score for Saveleva, morphological damage to the trunk, the description of the crown architectonics, the presence of morphogenetic and exogenous damage to the leaf blade, the population of the trunk pests, the presence of hollows, the wind feature and the loading of this site, the mode of visiting the territory (recreational load), the direction of possible fall, percentage of sound rot, modulus of elasticity of wood, density of wood, the ratio of biomass to critical mass, mechanical resistance to static and dynamic loads according to calculations on biomechanics. In the case study of a model tree (London plane) the applicability of this approach to landscaping practices is shown.

Keywords: hazardous trees; mechanical stability; visual diagnostics; modulus of elasticity (MOE); instrumental diagnostics; scale of accident; critical load; anthropogenic influence; age drill; Platanus acerifolia (Aiton) Willd.; static load; dynamic factor; wind.

\section{ОЦЕНКА ИЗМЕНЕНИЯ АКТУАЛЬНОЙ И ОБМЕННОЙ КИСЛОТНОСТИ ДЕРНОВО-ПОДЗОЛИСТОЙ ЛЕГКОСУГЛИНИСТОЙ ПОЧВЫ ПРИ ПРИМЕНЕНИИ ЦЕОЛИТА ХОТЫНЕЦКОГО МЕСТОРОЖДЕНИЯ}

Куликова Алевтина Христофоровна, доктор сельскохозяйственных наук, заведующий кафедрой почвоведения, агрохимии и агроэкологии Ульяновский государственный аграрный университет имени П.А. Стольпина (2. Ульяновск, Российская Федерация)

Козлов Андрей Владимирович, кандидат биологических наук, доцент кафедры экологического образования и рационального природопользования Уромова Ирина Павловна, доктор сельскохозяйственных наук, профессор кафедры биологии, химии и биолого-химического образования Нижегородский государственный педагогический университет имени Козьмы Минина (2. Нижний Новгород, Российская Федерация)

Аннотация. В данной статье рассматривается степень влияния цеолитовой породы Хотынецкого месторождения на показатели актуальной и обменной кислотности дерново-подзолистой легкосуглинистой почвы Нижегородской области. Трехлетний эксперимент, представляя собой микрополевой опыт, был заложен в 
2014 году в условиях ООО «Элитхоз» Борского района. Цеолит вносили в пахотных горизонт однократно в высоких дозах - 3, 6 и 12 т/га. В течение лет исследований (2015-2017 гг.) на делянках выращивали районированные сорта основных сельскохозяйственных культур региона. Почвенную кислотность оценивали по показателям $\mathrm{pH}$, определенным из водной и солевой вытяжек подготовленной к анализам почвы, которую отбирали в осенний период после уборки урожая культурных растений. В результате проведенных исследований было установлено положительное действие всех доз изучаемого цеолита на показатели кислотноосновного режима дерново-подзолистой почвы. Существенный эффект прослеживался уже при минималь-

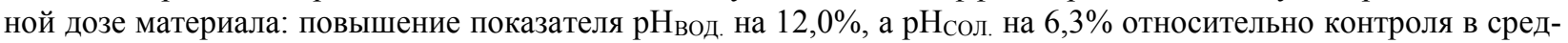
нем по годам исследования. Применение 6 т/га цеолитовой породы в наибольшей мере способствовало уменьшению актуальной кислотности почвы на 20\%, обменной кислотности - на $13 \%$, а также на $60 \%$ - повышению ионной обменности системы «почва-раствор» с сохранением силы своего действия в течение трех лет исследования.

Ключевые слова: цеолитовая порода Хотынецкого месторождения; дерново-подзолистая легкосуглинистая почва; актуальная кислотность; обменная кислотность; ионная обменность; система «почва-раствор»; кислотно-основное состояние; почвенно-поглощающий комплекс; обменные соединения кальция и магния.

\section{Введение}

Динамика растворимости и связывания различных ионов между почвенным раствором и почвеннопоглощающим комплексом (ППК) является ключевым набором процессов, определяющих окислительно-восстановительное состояние почвы и, как следствие, жизнеобеспеченность почвообитающих организмов, в том числе их микроскопических форм, а также высших растений. Поэтому кислотно-основное равновесие в профиле почвенного тела является генеральным аспектом, востребованным в изучении при влиянии на него различных агромероприятий.

В настоящее время [1] особую актуальность приобрело изучение поведения природных кремнийсодержащих материалов в почвах различных климатических зон, которые зачастую представляют собой сыромолотые породы различного происхождения и свойств, применяемые в земледелии в качестве нетрадиционных удобрений и мелиорантов. Данные вещества способствуют оптимизации показателей эффективного плодородия почв [2-8] и, как следствие, повышению продуктивности посевов [9-13], повышению устойчивости сельскохозяйственных культур к болезням и вредителям [14; 15], а также существенной трансформации почвенно-биотического комплекса [16; 17]. Подобная комплексность воздействия природных высококремнистых материалов на систему «почва-растение» определяет еще больший интерес к изучению их взаимодействия с почвообитающей микробиотой и с ППК, являющимися главными звеньями формирования почвенного тела.

Целью данной работы явилась оценка изменения актуальной и обменной кислотности дерново-подзолистой легкосуглинистой почвы Нижегородской области в зависимости от дозы цеолита Хотынецкого месторождения.

\section{Объекты исследования}

Объектами исследования явились цеолит Хотынецкого месторождения (Орловская область) и дерново-подзолистая легкосуглинистая почва в условиях Нижегородской области.

Цеолиты представляют собой набор алюмосиликатных минералов различной степени гидратированности, которые в зависимости от доминирующего минерала в составе подразделяются на клиноптилолитовый, морденитовый, филлипситовый и шабазитовый типы цеолитовых пород. Все они обладают комплексом свойств, ионная обменность и каталитическая способность из которых являются наиболее значимыми с точки зрения агрономического почвоведения. Некоторые свойства Хотынецкой цеолитовой породы отражены в таблице 1 в виде химического состава [18].

Таблица 1 - Обобщенный химический состав Цеолита Хотынецкого месторождения

\begin{tabular}{|l|c|c|c|c|c|c|}
\hline \multirow{2}{*}{ Порода } & \multirow{2}{*}{ ИЕ* } & \multicolumn{5}{|c|}{ Элемент в оксидной форме (на абс.-сух. вещество) } \\
\cline { 3 - 7 } & & $\mathrm{SiO}_{2}$ & $\mathrm{P}_{2} \mathrm{O}_{5}$ & $\mathrm{~K}_{2} \mathrm{O}$ & $\mathrm{CaO}$ & $\mathrm{MgO}$ \\
\hline Цеолит & \multirow{2}{*}{48} & 56,6 & & & & \\
- валовая форма, \% & & 7950 & 260 & 1,82 & 13,3 & 1,90 \\
- подвижная форма, мг/кг & & & 250 & 4800 & 1600 \\
\hline
\end{tabular}

Примечание. *- ионообменная емкость, мг-экв./100 г.

Почва поля - дерново-подзолистая среднедерновая неглубокооподзоленная неоглеенная легкосуглинистая [19], обладающая среднекислой реакцией $\left(\mathrm{pH}_{\mathrm{KCl}} 4,8\right.$ ед. $\left.\mathrm{pH}\right)$, низким содержанием гумуса $(1,21 \%)$, средним содержанием подвижных соединений фосфора и калия (соответственно 86 и 110 мг/кг по Кирсанову), а также средним уровнем дефицита в балансе - актуального и потенциального кремния (соответственно 16 и 213 мг/кг по Матыченкову).

\section{Материалы и методика исследований}

Эксперимент представлял собой микрополевой опыт, заложенный в 2014 году в условиях картофелеводческого хозяйства ООО «Элитхоз» в Борском районе Нижегородской области. Схема опыта вклю- чала вариант естественного плодородия почвы (Контроль), а также варианты с внесением в почву высоких доз цеолита - из расчета 3 т/га (Цеолит-1), 6 т/га (Цеолит-2) и 12 т/га (Цеолит-3). Породы вносили однократно в летний период 2014 года при разбивке участка на делянки. В годы испытаний выращивалась озимая пшеница сорта Московская 39 (2015 г.), ячмень сорта Велес (2016 г.) и горох посевной сорта Чишминский 95 (2017 г.). Агротехника выращивания культур - общепринятая для микрополевых экспериментов, все работы проводились вручную. Учетная площадь делянки - $1 \mathrm{M}^{2}$, расположение делянок рендомизированное, повторность в опытах - четырехкратная. 
Куликова А.Х., Козлов А.В., Уромова И.П.

Образцы почвы отбирали в дни уборки урожая культур: точечные - методом конверта из пяти точек с делянки, соединяя их в один объединенный образец. Далее почвенные образцы высушивали, подготавливали к анализу путем отбора посторонних включений, размола и просеивания через сито с диаметром ячеек в 1 мм. Затем в образцах определяли актуальную и обменную кислотность в виде измерения $\mathrm{pH}$ водной и солевой вытяжек (дистиллированная вода и $0,1 \mathrm{H}$ раствор $\mathrm{KCl}$ соответственно) по ГОСТ 26483-85 [20] на рН-метре-милливольтметре MAPK-903.

Математическую обработку полученных данных проводили методом дисперсионного анализа по Б.А. Доспехову [21] с использованием программного пакета Microsoft Office Excel.

\section{Результаты исследований и их обсуждение}

Под кислотностью почвы понимается ее способность проявлять кислотные свойства в отношении воды почвенного раствора, минеральной и органической частей почвы и обитающих в ней организмов [22]. Кислую реакцию почве придает наличие ионов водорода $\left(\mathrm{H}^{+}\right)$в почвенном растворе, а также обменных ионов водорода $\left(\mathrm{H}^{+}\right)$, алюминия $\left(\mathrm{Al}^{3+}\right)$, железа $\left(\mathrm{Fe}^{2+}, \mathrm{Fe}^{3+}\right)$ и марганца $\left(\mathrm{Mn}^{2+}\right)$ в почвенном поглоща- ющем комплексе при неполной их нейтрализации гидроксид-анионами $\left(\mathrm{OH}^{-}\right)$, а также катионами кальция $\left(\mathrm{Ca}^{2+}\right)$, магния $\left(\mathrm{Mg}^{2+}\right)$ и натрия $\left(\mathrm{Na}^{+}\right)$.

Актуальная (активная) кислотность почвы - это кислотность почвенного раствора, то есть непосредственно жидкой фазы почвы (свободной воды). Она обусловлена, главным образом, наличием в растворе почвы свободных органических и минеральных кислот (щавелевая, лимонная и угольная кислоты, фульвокислоты, а также гидролитически кислые соли). Несмотря на высокую динамичность показателя, зависимую от множества факторов, актуальная кислотность показывает кислотное состояние свободной жидкости в почвенной массе, что значимо для оценки первичного кислотно-основного состояния почвы.

Данные таблицы 2 отражают состояние актуальной кислотности дерново-подзолистой почвы в зависимости от дозы цеолитовой породы.

В результате проведенных исследований было установлено значительное нейтрализующее влияние цеолита на актуальное кислотное состояние почвы. Так, уже при минимальной дозе в 3 т/га показатель рН Вод. повышался на $11 \%$ по отношению к контролю с сохранением аналогичной закономерности на 2-й и 3 -й годы исследования (на $12 \%$ и $13 \%$ соответственно).

таблица 2 - Динамика актуальной кислотности дерново-подзолистой легкосуглинистой почвы в горизонте Апах в зависимости от дозы цеолитовой породы

\begin{tabular}{|c|c|c|c|c|c|c|c|c|}
\hline \multirow[b]{2}{*}{ Вариант } & \multicolumn{2}{|c|}{2015 год } & \multicolumn{2}{|c|}{2016 год } & \multicolumn{2}{|c|}{2017 год } & \multicolumn{2}{|c|}{ В среднем за 3 года } \\
\hline & $\begin{array}{l}\text { pH }{ }_{\text {вод., }} \\
\text { ед. } \mathrm{pH}\end{array}$ & \pm к контр. & $\begin{array}{l}\mathrm{pH} \mathrm{BOд.,} \\
\text { ед. } \mathrm{pH}\end{array}$ & \pm к контр. & $\begin{array}{l}\mathrm{pH} \mathrm{BOд.,} \\
\text { ед. } \mathrm{pH}\end{array}$ & \pm к контр. & $\begin{array}{l}\text { pH } \\
\text { едод. } \mathrm{pH}\end{array}$ & \pm к контр \\
\hline Контроль & 5,88 & - & 5,96 & - & 5,92 & - & 5,92 & - \\
\hline Цеолит-1 & 6,54 & 0,66 & 6,66 & 0,70 & 6,71 & 0,79 & 6,64 & 0,72 \\
\hline Цеолит-2 & 6,97 & 1,09 & 7,03 & 1,07 & 7,09 & 1,17 & 7,03 & 1,11 \\
\hline Цеолит-3 & 6,93 & 1,05 & 6,99 & 1,03 & 7,04 & 1,12 & 6,99 & 1,07 \\
\hline $\mathrm{HCP}_{0}$ & & 0,31 & & 0,34 & & 0,15 & & - \\
\hline
\end{tabular}

Максимальное снижение актуальной кислотности почвы прослеживалось на варианте со 2-й дозой цеолитовой породы - на $19 \%, 18 \%$ и $20 \%$ относительно контроля по годам исследования. Однако на варианте с наибольшей дозой степень данного влияния оставалась на уровне варианте с внесением в почву 6 т/га материала. В среднем за 3 года проведенного эксперимента прослеживалась аналогичная закономерность.

Нужно отметить сохранение тенденции положительного влияния цеолита на нейтрализацию кислотных катионов в жидкой фазе почвы в течение всех лет проведения эксперимента.
Обменная кислотность почвы обусловлена катионами водорода $\left(\mathrm{H}^{+}\right)$, алюминия $\left(\mathrm{Al}^{3+}\right)$ и железа $\left(\mathrm{Fe}^{2+}\right.$, $\mathrm{Fe}^{3+}$ ), входящими в диффузный слой коллоидных мицелл ППК почвы, которые, в свою очередь, определяют реальный кислотно-основной обмен при взаимодействии твердой фазы почвы с почвенным раствором. В богатых перегноем и гумусом горизонтах она обусловлена преимущественно катионами $\mathrm{H}^{+}$, в малогумусных минеральных - катионами $\mathrm{Al}^{3+}, \mathrm{Fe}^{2+}$ и $\mathrm{Fe}^{3+}$.

В таблице 3 показано изменение показателя обменной кислотности дерново-подзолистой почвы при ее взаимодействии с цеолитом Хотынецкого месторождения.

Таблица 3 - Динамика обменной кислотности дерново-подзолистой легкосуглинистой почвы в горизонте Апах В зависимости от дозы цеолитовой породы

\begin{tabular}{|l|c|c|c|c|c|c|c|c|}
\hline \multirow{2}{*}{ Вариант } & \multicolumn{2}{|c|}{2015 год } & \multicolumn{2}{c|}{2016 год } & \multicolumn{2}{c|}{2017 год } & \multicolumn{2}{c|}{ В среднем за 3 года } \\
\cline { 2 - 9 } & $\begin{array}{c}\mathrm{pH} \text { сол., } \\
\text { ед. } \mathrm{pH}\end{array}$ & \pm к контр. & $\begin{array}{c}\mathrm{pH} \text { сол., } \\
\text { ед. } \mathrm{pH}\end{array}$ & \pm к контр. & $\begin{array}{c}\mathrm{pH} \text { Сол., } \\
\text { ед. } \mathrm{pH}\end{array}$ & \pm к контр. & $\begin{array}{c}\mathrm{pH} \text { сол., } \\
\text { ед. } \mathrm{pH}\end{array}$ & \pm к контр. \\
\hline Контроль & 4,81 & - & 4,90 & - & 4,86 & - & 4,86 & - \\
\hline Цеолит-1 & 5,04 & 0,23 & 5,17 & 0,27 & 5,27 & 0,41 & 5,16 & 0,30 \\
Цеолит-2 & 5,21 & 0,40 & 5,31 & 0,41 & 5,49 & 0,63 & 5,34 & 0,48 \\
Цеолит-3 & 5,16 & 0,35 & 5,28 & 0,38 & 5,36 & 0,50 & 5,27 & 0,41 \\
\hline HСР $_{05}$ & \multicolumn{3}{|c|}{0,09} & \multicolumn{3}{|c|}{0,27} & & - \\
\hline
\end{tabular}

Прежде всего, нужно отметить, что степень изменения рассматриваемого показателя оказалась более сдержанной по сравнению с его аналогом, определенным из водной вытяжки. Это говорит о наличии 
процессов обмена между жидкой фазой почвы и ее коллоидной системой, на которые также оказал свое действие цеолит во всех изучаемых дозах. Например, если при минимальной дозе породы (3 т/га) в течение трех лет исследования отмечалась только позитивная

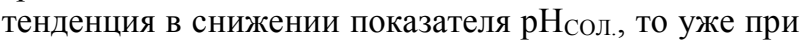
повышении дозы в 2 раза (6 т/га) была отмечена закономерность снижения обменной кислотности почвы - от 8\% (2015-2016 гг.) до 13\% (2017 г.). Вариант с наибольшей дозой материала не оказал еще большего влияния на показатель по сравнению с предыдущим вариантом со средней дозой, что также было зафиксировано в среднем по трем годам исследова- ния: максимальный эффект нейтрализации кислотных катионов цеолит оказал на варианте с внесением в почву 6 т/га породы.

Поскольку показатели актуальной и обменной кислотности отражают степень перехода кислотообразующих катионов в почвенный раствор, а их разница показывает интенсивность обмена между ППК и свободной водой в почве, оценка изменения ионной обменности системы «почва-раствор» позволяет судить о наличии прямого влияния изучаемой породы на кислотно-основное равновесие в почвенной массе (табл. 4).

Таблица 4 - Динамика показателя ионной обменности системы «почва-раствор» дерново-подзолистой легкосуглинистой почвы в горизонте АпАх в зависимости от дозы цеолитовой породы

\begin{tabular}{|c|c|c|c|c|c|c|c|c|}
\hline \multirow[b]{2}{*}{ Вариант } & \multicolumn{2}{|c|}{2015 год } & \multicolumn{2}{|c|}{2016 год } & \multicolumn{2}{|c|}{2017 год } & \multicolumn{2}{|c|}{ В среднем за 3 года } \\
\hline & $\begin{array}{l}\Delta \mathrm{pH}, \\
\text { ед. } \mathrm{pH}\end{array}$ & \pm к контр. & $\begin{array}{l}\Delta \mathrm{pH}, \\
\text { ед. } \mathrm{pH}\end{array}$ & \pm к контр. & $\begin{array}{l}\Delta \mathrm{pH}, \\
\text { ед. } \mathrm{pH}\end{array}$ & \pm к контр. & $\begin{array}{l}\Delta \mathrm{pH}, \\
\text { ед. } \mathrm{pH}\end{array}$ & \pm к контр. \\
\hline Контроль & 1,07 & - & 1,06 & - & 1,06 & - & 1,06 & - \\
\hline Цеолит-1 & 1,50 & 0,43 & 1,49 & 0,43 & 1,44 & 0,38 & 1,48 & 0,42 \\
\hline Цеолит-2 & 1,77 & 0,70 & 1,72 & 0,66 & 1,61 & 0,55 & 1,70 & 0,64 \\
\hline Цеолит-3 & 1,77 & 0,70 & 1,71 & 0,65 & 1,68 & 0,62 & 1,72 & 0,66 \\
\hline $\mathrm{HCP}_{05}$ & & 0,36 & & 0,29 & & 0,34 & & - \\
\hline
\end{tabular}

Выявлено, что внесение цеолита в почву способствовало сдвигу кислотно-основной системы почвенного раствора в щелочную сторону диапазона $\mathrm{pH}$ с наибольшим эффектом действия каждой из рассматриваемых доз в 1-й год испытаний. Нужно также отметить, что помимо как такового наличия эффекта изменения ионной обменности системы «почвараствор» от внесения цеолита в эксперименте установлено положительное влияние его первых двух доз на рассматриваемый показатель.

Подобные закономерности, очевидно, обусловлены высоким содержанием в породе кальция (до $13,3 \%$ ) и магния (до 1,9\%) и, в особенности, их подвижных соединений (соответственно 4800 и 1600 мг/кг). Как известно [23], ионы данных элементов в первую очередь способствуют снижению кислотности почвы, поскольку как напрямую нейтрализуют высвобождаемые из ППК кислотные катионы в жидкой фазе почвы, так и замещают их в самих коллоидах, тем самым подщелачивая состав почвенных мицеллярных структур.

\section{Выводы}

В результате проведенных исследований установлено положительное действие цеолита Хотынецкого месторождения на показатели кислотно-основного режима дерново-подзолистой легкосуглинистой почвы Нижегородской области. Применение 6 т/га цеолитовой породы в наибольшей степени способствовало уменьшению актуальной кислотности почвы на $20 \%$, обменной кислотности - на $13 \%$, а также на $60 \%$ повышению ионной обменности системы «почва-раствор» с сохранением силы своего действия в течение трех лет исследования. Таким образом, положительный эффект в отношении нейтрализации избыточной кислотности дерново-подзолистой почвы позволяет расценивать применение цеолита в качестве химического мелиоративного приема.

\section{Список литературы:}

1. Сяо В., Пенгбо 3., Бочарникова Е.А., Матыченков В.В., Х Хомяков Д.М., Пахненко Е.П. Влияние аморфного диоксида кремния на поведение кадмия в системе почва-растения риса // Вестник Московского университета. Серия 17: Почвоведение. 2018. № 2. C. $40-45$.

2. Агафонов Е.В., Хованский М.В. Влияние бентонита на повышение плодородия чернозема обыкновенного // Почвоведение. 2014. № 5. С. 597-601.

3. Бочарникова Е.А., Матыченков В.В., Погорелов А.Г. Сравнительная характеристика некоторых кремниевых удобрений // Агрохимия. 2011. № 11. C. $25-30$.

4. Капранов В.Н. Диатомит как кремнийсодержащее удобрение // Плодородие. 2006. № 4. С. 12-13.

5. Лобода Б.П., Яковлева Н.Н. Диатомиты и трепелы как почвоулучшители и источники биогенных элементов // Плодородие. 2003. № 5. С. 11-14.

6. Матыченков И.В., Пахненко Е.Н. Изменение содержания подвижных фосфатов почвы при внесении активных форм кремния // Вестник УГСХА. 2013. № 3 (23). C. 24-28.

7. Самсонова Н.Е. Роль кремния в формировании фосфатного режима дерново-подзолистых почв // Агрохимия. 2005. № 8. С. 11-18.

8. Шеуджен А.Х., Шхапацев А.К., Бочко Т.Ф. Влияние цеолитов на агрохимические показатели плодородия лугово-черноземной почвы и урожайность риса // Агрохимия. 2002. № 8. С. 14-20.

9. Лобода Б.П., Багдасаров В.Р., Фицуро Д.Д. Влияние удобрения на основе цеолитсодержащих трепелов Хотынецкого месторождения на урожайность и качество картофеля // Агрохимия. 2014. № 3. C. 28-35.

10. Козлов А.В., Куликова А.Х., Яшин Е.А. Роль и значение кремния и кремнийсодержащих веществ в агроэкосистемах // Вестник Мининского университета. 2015. № 2 (10). С. 23.

11. Матыченков В.В., Бочарникова Е.А., Аммосова Я.М. Влияние кремниевых удобрений на растения и почву // Агрохимия. 2002. № 2. С. 86-93.

12. Матыченков В.В. Роль подвижных соединений кремния в растениях и в системе почва-ра- 
Куликова А.Х., Козлов А.В., Уромова И.П.

стение: автореф. дис. ... д-ра биол. наук. Пущино, 2008.34 c.

13. Pirzad A., Mohammadzadeh S. Zeolite use efficiency variation under water deficit stress in grass pea and lentil // Журнал Сибирского федерального университета. Серия: Биология. 2016. № 9 (3). С. 291303.

14. Белоусов В.С. Применение цеолитсодержащей породы как сорбента аммиака и пестицидов из водных сред // Агрохимия. 2005. № 8. С. 65-69.

15. Козлов А.В., Уромова И.П., Фролов Е.А., Мозолева К.Ю. Физиологическое значение кремния в онтогенезе культурных растений и при их защите от фитопатогенов // Международный студенческий научный вестник. 2015. № 1. С. 39.

16. Козлов А.В., Куликова А.Х. Влияние высококремнистых пород на структуру, численность и ферментативную активность целлюлозосапротрофного микробного пула дерново-подзолистой почвы в условиях выращивания озимой пшеницы и картофеля // Вестник Ульяновской государственной сельскохозяйственной академии. 2016. № 1 (33). С. 56-65.
17. Козлов А.В. Экологическая оценка влияния диатомита на фитоценоз и состояние почвеннобиотического комплекса светло-серой лесной легкосуглинистой почвы: дис. ... канд. биол. наук. Н. Новгород, 2013. $182 \mathrm{c.}$

18. Дистанов У.Г. Минеральное сырье. Опалкристобалитовые породы: справочник. М.: Геоинформарк, 1998. 27 с.

19. Рабочая классификация почв Горьковской области / под ред. Б.А. Никитина. Горький: ГСХИ, $1990.87 \mathrm{c}$.

20. ГОСТ 26483-85. Почвы. Приготовление солевой вытяжки и определение ее $\mathrm{pH}$ по методу ЦИНАО. М.: Изд-во стандартов, 1986. 6 с.

21. Доспехов Б.А. Методика полевого опыта (с основами статистической обработки результатов исследований). М.: ИД Альянс, 2011. 352 с.

22. Добровольский Г.В., Никитин Е.Д. Экология почв. М.: Издательство МГУ, 2012. 412 с.

23. Зайдельман Ф.Р. Генезис и экологические основы мелиорации почв и ландшафтов. М.: Издательство КДУ, 2009. 720 с.

\title{
ASSESSMENT OF RELEVANT AND EXCHANGE ACIDITY OF CESPITOSE-PODSOLIC SANDY LOAMY SOIL WHEN THE HOTYNETSKY FIELD ZEOLITE IS USED
}

\author{
Kulikova Alevtina Hristoforovna, doctor of agricultural sciences, \\ head of Soil Science, Agrochemistry and Agroecology Department \\ Ulyanovsk State Agrarian University named after P.A. Stolypin (Ulyanovsk, Russian Federation) \\ Kozlov Andrey Vladimirovich, candidate of biological sciences, \\ associate professor of Ecological Education and Rational Environmental Management Department \\ Uromova Irina Pavlovna, doctor of agricultural sciences, \\ professor of Biology, Chemistry and Biological and Chemical Education Department \\ Minin Nizhny Novgorod State Pedagogical University (Nizhny Novgorod, Russian Federation)
}

\begin{abstract}
The following paper considers influence extent of zeolite breed of the Hotynetsky field on indicators of relevant and exchange acidity of the cespitose-podsolic sandy loamy soil in the Nizhny Novgorod Region. A threeyear experiment, representing microfield experiment, was started in 2014 in the Borsky District «Elitkhoz». Zeolite was brought in the plough-layer once in high doses - 3, 6 and 12 t/hectare. During the research (2015-2017) on allotments the main crops of the region were grown up. The acidity of the soil was estimated on $\mathrm{pH}$ indicators, defined from water and salt extracts which were selected during the autumn period after cultural plants harvesting. As a result of the conducted researches positive action of all doses of the studied zeolite on indicators of the acid and main mode of the cespitose-podsolic soil was established. The essential effect was traced already at the minimum dose of material: $12,0 \%$ increase of $\mathrm{pH}_{\text {water }}$ indicator and 6,3\% increase of $\mathrm{pH}_{\text {salt }}$ indicator on average during the research time. Application of $6 \mathrm{t} /$ hectare of zeolite breed in the greatest measure promoted reduction of the relevant acidity of the soil by $20 \%$, exchange acidity - for $13 \%$ and also for $60 \%$ - to increase in an ionic exchanging of the soil solution system with preservation of the action force during the research time.

Keywords: zeolite breed of Hotynetsky field; cespitose-podsolic sandy loamy soil; relevant acidity; exchange acidity; ionic exchanging; soil solution system; acid and main state; soil absorbing complex; exchange compounds of calcium and magnesium.
\end{abstract}

УДК 591.9: 598.2

Статья поступила в редакцию 09.04.2018

\section{СТРУКТУРА И ФАКТОРЫ ФОРМИРОВАНИЯ РАЗНООБРАЗИЯ ПТИЦ ЛЕСНЫХ МЕСТООБИТАНИЙ РОССИЙСКОГО ПРИИШИМЬЯ}

Левых Алёна Юрьевна, кандидат биологических наук, доцент кафедры биологии, географии и методики их преподавания

Болдырев Степан Леонидович, аспирант кафедры биологии, географии и методики их преподавания Ииимский педагогический институт имени П.П. Ершова (филиал)

Тюменского государственного университета (г. Ииим, Тюменская область, Российская Федераџия)

Аннотащия. На основе материалов полевых учётов птиц, проведённых в сезоны 2014-2016 гг. на 28 постоянных маршрутах в лесных местообитаниях Российского Приишимья, исследована связь между отдель- 